\title{
Caracterização e destinação ambientalmente corretas do lodo gerado pelas estações de tratamento de água
}

O lodo gerado pelas estações de tratamento de água é o resíduo formado durante o processo de transformação da água bruto em água potável por meio dos processos de coagulação, floculação decantação e filtragem. Este resíduo de características tóxicas, portanto, tem sua destinação compatível com as diretrizes da PNRS - Lei 12.305/2010, priorizando a possibilidade de redução, reuso e reciclagem. Assim, o presente trabalho tem por objetivo fazer uma revisão sobre o lodo gerado pelas Estações de Tratamento de Água, e sugerir alternativas de reutilização deste resíduo de forma ambientalmente correta. Este trabalho foi construído por meio de revisão bibliográficas, com objetivo de descrever a problemática do lodo e ETA e sugerir meios ambientalmente correto para destinação deste resíduo. Dentre as alternativas, podemos destacar a utilização do lodo em solos agrícolas, cujas melhorias são estruturais do solo; ajuste de pH; adição de traços de minerais; aumento da capacidade de retenção de água e melhoria das condições de aeração do solo. Na produção de mudas, pode contribuir para o fornecimento de nutrientes e matéria orgânica para planta. Outras destinações ainda podem ser adotadas, como produção de cerâmica lançamento na rede de esgoto doméstico ou em aterro sanitário. Tendo em vista as restrições da legislação para lançamento dos resíduos de ETAs em corpos d'água, o volume de água perdido e os impactos ambientais associados a essa prática, há uma crescente necessidade de proporcionar uma destinação adequada ou um uso produtivo a esses resíduos, minimizando também a quantidade de subproduto gerado. Deste modo, é necessário um estudo da disposição final adequada deste resíduo a fim de contribuir para a minimização dos impactos ambientais evitando que o lodo seja lançado in natura nos corpos hídricos.

Palavras-chave: Resíduo de ETA; Impacto ambiental; Produção de mudas; Metais pesados.

\section{Environmentally friendly characterization and disposal of sludge generated by water treatment plants}

\begin{abstract}
Sludge generated by water treatment plants is the waste formed during the process of transforming raw water into drinking water through coagulation, flocculation, decantation and filtration processes. This waste with toxic characteristics, therefore, has its destination compatible with the guidelines of PNRS - Law 12.305 / 2010, prioritizing the possibility of reduction, reuse and recycling. Thus, this paper aims to review the sludge generated by water treatment plants, and to suggest alternatives for reusing this waste in an environmentally sound manner. This work was built through bibliographic reviews, aiming to describe the problem of sludge and ETA and to suggest environmentally correct means for disposal of this waste. Among the alternatives, we can highlight the use of sludge in agricultural soils, whose improvements are structural soil; $\mathrm{pH}$ adjustment; addition of trace minerals; increased water retention capacity and improved soil aeration conditions. In seedling production, it can contribute to the supply of nutrients and organic matter to the plant. Other destinations may still be adopted, such as production of ceramics released into the domestic sewage system or landfill. In view of the restrictions in the legislation for the disposal of waste water from ETAs into bodies of water, the volume of water lost and the environmental impacts associated with this practice, there is a growing need to provide appropriate disposal or productive use of such waste, also minimizing the amount of byproduct generated. Thus, it is necessary to study the proper final disposal of this waste in order to contribute to the minimization of environmental impacts by preventing sludge from being released in natura to water bodies.
\end{abstract}

Keywords: Waste from ETA; Environmental impact; Seedling production; Heavy metals.

Topic: Desenvolvimento, Sustentabilidade e Meio Ambiente

Reviewed anonymously in the process of blind peer.

Geremias Dourado da Cunha

Universidade Federal de Rondônia, Brasil http://lattes.cnpq.br/1897564799872972 http://orcid.org/0000-0002-3172-5536

geremiasdarwin@gmail.com

Jerri Adriano Vieira Lima

Universidade Federal de Rondônia, Brasil http://lattes.cnpq.br/3607713824499216 geremiasdarwin@gmail.com

\section{Rosalvo Stachiw (id}

Universidade Federal de Rondônia, Brasil

http://lattes.cnpq.br/1646641940410936

http://orcid.org/0000-0001-6901-3852

geremiasdarwin@gmail.com

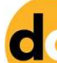

DOI: 10.6008/CBPC2318-2881.2019.002.0003
Received: 03/06/2019

Approved: 07/08/2019

Kênia Michele de Quadros Tronco (ib)

Universidade Federal de Rondônia, Brasil

http://lattes.cnpq.br/2209314957208420

http://orcid.org/0000-0003-0873-9582

geremiasdarwin@gmail.com

\section{Referencing this:}

CUNHA, G. D.; LIMA, J. S. V.; STACHIW, R; TRONCO, K. M. Q..

Caracterização e destinação ambientalmente corretas do lodo gerado pelas estações de tratamento de água. Nature and Conservation, v.12, n.2, p.19-30, 2019. DOI: http://doi.org/10.6008/CBPC2318$\underline{2881.2019 .002 .0003}$ 


\section{INTRODUÇÃO}

O lodo gerado pelas estações de tratamento de água é o resíduo formado durante o processo de tratamento da água bruta em água potável por meio dos processos de coagulação, floculação decantação e filtragem. Durante o processo de coagulação, as partículas são desestabilizadas e agregadas em si, formando flóculos que, por gravidade, são sedimentadas nos tanques de decantação, e parte destes flóculos que não foram sedimentados, são retidos no processo de filtragem.

Este lodo é o resultado do aglomerado das substâncias retiradas da água durante o processo de tratamento, que pode variar de acordo com o tipo de coagulante utilizado durante o processo de tratamento, em razão de que diferentes locais de retirada de água bruta garantem propriedades distintas e, logo, diferentes dosagens de coagulantes. Quanto maior for a deterioração da água, maior será a quantidade de produtos utilizados durante o tratamento (OLIVEIRA et al., 2016).

A destinação deste material residual é um grande problema ambiental para as empresas de saneamento, públicas ou privadas. Quando deixados ao acaso, pode ocorrer o desperdício hídrico, pois parte da água se perde nos rios e em outros canais de escoamento, e o resíduo sólido não tratado contaminaria o meio ambiente onde é descartado (SUGUINO et al. 2013).

A prática mais simples a ser adotada é a disposição dos lodos em aterros sanitários ou a devolução do resíduo para o próprio rio onde foi coletada a água bruta. O lançamento in natura nos corpos hídricos constitui-se em crime ambiental, de acordo com a Lei no 9.605/98, a qual estabelece penalizações a aqueles que, por meio de afluentes ou carreamento de materiais poluentes, provocarem o perecimento de espécie da fauna aquática existentes em rios, lagos, açudes, lagoas, baías ou águas jurisdicionais brasileiras (SILVA et al., 2010).

Além disso, legislações cada vez mais restritivas, altos custos de transporte e disposição final, bem como a escassez de áreas adequadas em regiões altamente urbanizadas, têm levado pesquisadores e técnicos à busca de soluções mais econômicas e inteligentes para o uso e disposição final dos lodos (JANUARIO et al., 2007).

Em linhas gerais, um dos desafios para as empresas de saneamento é a adoção de alternativas adequadas para a destinação final do lodo gerado nas Estações de Tratamento de Água (ETA) sob os aspectos: econômico, técnico e ambiental (BITTENCOURT, 2012). Alguns benefícios associados à aplicação dos lodos de ETAs em solos agrícolas são: melhoria estrutural do solo; ajuste de $\mathrm{pH}$; adição de traços de minerais; aumento da capacidade de retenção de água e melhoria das condições de aeração do solo. Porém, estudos têm demonstrado que o lodo de ETAs, quando aplicado ao solo agrícola, apresenta tendência de reagir e indisponibilizar à planta, o fósforo presente no solo (TSUTYA, 2001). Assim, o presente trabalho tem por objetivo fazer uma revisão sobre o Lodo gerado pelas Estações de Tratamento de Água e sugerir alternativas de reutilização deste resíduo de forma ambientalmente correta. 


\section{METODOLOGIA}

O lodo de gerado em Estações de Tratamento de Água é um resíduo rico em matéria orgânica e nutriente cuja disposição final em grande parte das ETAs contraria a Política Nacional de Resíduos Sólidos (PNRS), disposta pela Lei no 12.305 (BRASIL, 2010). Sendo assim, o presente trabalho faz uma breve revisão na classificação do lodo de ETA, demonstrando aspectos positivos bem como a viabilidade de reutilização deste resíduo. Por fim, propõe alternativa ambientalmente correta para destinação deste resíduo, de modo a minimizar os impactos causado ao meio aquático.

\section{DISCUSSÃO TEÓRICA}

Aspectos gerais sobre a característica e classificação do lodo gerado pelas Estações de Tratamento de Água

O objetivo fundamental das Estações de Tratamento de Água para abastecimento público tem sido produzir água biologicamente e quimicamente segura para o consumo humano, bem como, esteticamente agradável. Para isso, utiliza vários processos e operações que, mediante a introdução de produtos químicos, transformam a água bruta, normalmente inadequada para o consumo humano, em água de acordo com os padrões de potabilidade exigidos (figura 1). Todo este processo gera, como subprodutos, uma elevada quantidade de resíduos (JANUARIO et al., 2007)

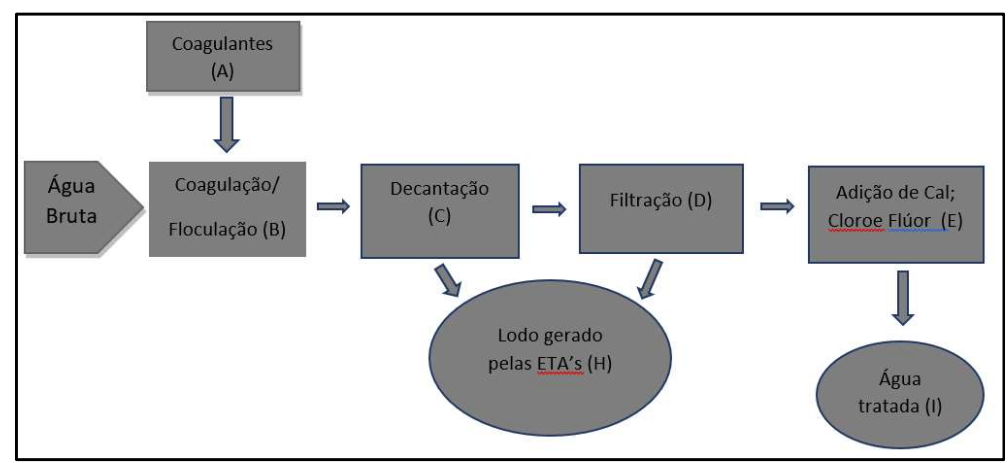

Figura 1: Fluxograma do tratamento de água e produção de lodo numa Estação de Tratamento de Água.

Este resíduo, também chamado de lodo, contém, basicamente, compostos químicos, que são resultantes do processo de adição de tratamento no processo de coagulação da água, partículas inorgânicas como areia, silte e argila, coloides de cor e outros materiais orgânicos, incluindo plânctons que são removidos da água bruta para o seu tratamento (FIGUEIREDO NETO, 2011).

Em termos de características físicas, o teor de sólidos do lodo de ETA varia de 0,1 a 4\%, sendo estes, 75 a 90\% sólidos suspensos e 20 a 35\% compostos voláteis, além de estarem presentes os hidróxidos de metais resultantes dos produtos do coagulante utilizado. Portanto, é necessário que sua disposição final seja adequada ambientalmente conforme as normas (RICHTER, 2009).

Porém, destaca-se que os lodos possuem características distintas, pois dependem fundamentalmente das condições apresentadas pela água bruta e dos tipos de coagulantes químicos e 
demais produtos que são utilizados no tratamento de água. A forma como ocorre a limpeza dos decantadores também pode influenciar no perfil do lodo de ETA (ANDRADE et al., 2014).

Os sais de alumínio e ferro que são empregados no tratamento de água são agentes inorgânicos não biodegradáveis, que acrescentam elementos químicos à água ou ao lodo. Os sais de ferro são, também, muito utilizados como agentes coagulantes para tratamento de água. Reagem de forma a neutralizar cargas negativas dos coloides, e proporcionam a formação de hidróxidos insolúveis de ferro (VAZ et al., 2010). Os mais comuns são o sulfato de alumínio, sulfato férrico e cloreto férrico, os hidróxidos desses metais precipitam, formando resíduos, sendo esta uma grande preocupação das ETAs, que buscam melhorar o processo de coagulação e minimizar a geração de resíduos (KLOC et al., 2017).

O sulfato de alumínio é um coagulante amplamente utilizado pelas Estações de Tratamento de Água, e sua eficiência aumenta com o aumento da temperatura da água, podendo ser testada em localidades onde a temperatura da água se apresenta mais elevada na maior parte do dia (SCALIZE et al., 2012). O sulfato de alumínio em solução é um ácido, e é corrosivo devendo ser armazenado em tanques de madeira, chumbo, ou com revestimento de borracha, plástico, epóxi ou aço inoxidável (RICHTER, 2009). Pode ser fornecido seco, em pedras, granular ou líquido.

A ABNT NR 10004 classifica o lodo de ETA como resíduos sólidos os resíduos nos estados sólido e semissólido, que resultam de atividades de origem industrial, doméstica, hospitalar, comercial, agrícola, de serviço e de varrição. Ficam incluídos nesta definição os lodos provenientes dos sistemas tratamento de água. O lodo de sulfato de alumínio é um líquido não-newtoniano, quando em repouso, apresenta-se em estado coloidal, cuja fração é formada de hidróxido de alumínio, partículas inorgânicas, coloides de cor e bactérias (RICHTER, 2001). Ele pode apresentar as seguintes características, de acordo com a tabela 1. Já o lodo proveniente da coagulação com sais de ferro, que apresenta características similares ao de sulfato de alumínio, é estabelecido pela tabela 2.

Tabela 1: Características típicas do lodo de sulfato de alumínio.

\begin{tabular}{|c|c|c|c|c|c|c|}
\hline Sólidos totais (\%) & $\begin{array}{c}\mathbf{A l}_{\mathbf{2}} \mathbf{O}_{\mathbf{3}} \mathbf{5} \mathbf{5} \mathbf{5 H}_{\mathbf{2}} \mathbf{O} \\
(\mathbf{\%})\end{array}$ & $\begin{array}{c}\text { Inorgânicos } \\
\text { (\%) }\end{array}$ & $\begin{array}{c}\text { Matéria orgânica } \\
\text { (\%) }\end{array}$ & $\mathbf{p H}$ & $\mathbf{D B O}$ (mg/l) & $\begin{array}{c}\text { DQO } \\
\text { (mg/l) }\end{array}$ \\
\hline $\mathbf{0 , 1 - 4}$ & $15-40$ & $35-70$ & $15-25$ & $6-8$ & $30-300$ & $30-5000$ \\
\hline
\end{tabular}

Fonte: Richter (2001).

Tabela 2: Características típicas do lodo de sais de ferro.

\begin{tabular}{|c|c|c|c|}
\hline Sólidos totais (\%) & Fe (\%) & Voláteis (\%) & pH \\
\hline $\mathbf{0 , 2 5 - 3 , 5}$ & $4,6-20,6$ & $5,1-14,1$ & $7,4-9,5$ \\
\hline
\end{tabular}

Fonte: Richter (2001).

Dependendo da quantidade de coagulante adicionada, do pH da mistura e da concentração de alguns íons na água, poderá ocorrer a formação de precipitados $\mathrm{Al}(\mathrm{OH})_{3}$ ou $\mathrm{Fe}(\mathrm{OH})_{3}$. Em linhas gerais, os flocos obtidos por meio destes mecanismos são maiores e sedimentam ou flotam com mais facilidade do que os flocos obtidos com a coagulação realizada no processo de adsorção e neutralização das cargas (BERNARDO et al., 2005). Dentre os metais presentes no lodo de ETA, a Resolução 430/2011 do CONAMA, estabelece valores máximos para o lançamento nos efluentes, conforme disposto na tabela 3. 
Tabela 3: padrão de lançamentos de efluentes em corpos aquáticos.

\begin{tabular}{|l|c|}
\hline \multicolumn{1}{|c|}{ Metais } & Valor máximo \\
\hline Arsênio & $0,5 \mathrm{mg} / \mathrm{L} \mathrm{As}$ \\
\hline Cádmio total & $0,2 \mathrm{mg} / \mathrm{Cd}$ \\
\hline Chumbo total & $0,5 \mathrm{mg} / \mathrm{Pb}$ \\
\hline Cobre dissolvido & $1,0 \mathrm{mg} / \mathrm{L} \mathrm{Cu}$ \\
\hline Cromo hexavalente & $0,1 \mathrm{mg} / \mathrm{L} \mathrm{Cr}+6$ \\
\hline Cromo trivalente & $1,0 \mathrm{mg} / \mathrm{L} \mathrm{Cr}{ }^{+3}$ \\
\hline Estanho total & $4,0 \mathrm{mg} / \mathrm{L} \mathrm{Sn}$ \\
\hline Ferro dissolvido & $15,0 \mathrm{mg} / \mathrm{L} \mathrm{Fe}$ \\
\hline Manganês dissolvido & $1,0 \mathrm{mg} / \mathrm{L} \mathrm{Mn}$ \\
\hline Mercúrio total & $0,01 \mathrm{mg} / \mathrm{L} \mathrm{Hg}$ \\
\hline Níquel total & $2,0 \mathrm{mg} / \mathrm{L} \mathrm{Ni}$ \\
\hline Prata total & $0,1 \mathrm{mg} / \mathrm{L} \mathrm{Ag}$ \\
\hline Selênio total & $0,30 \mathrm{mg} / \mathrm{L} \mathrm{Se}$ \\
\hline Zinco total & $5,0 \mathrm{mg} / \mathrm{L} \mathrm{Zn}$ \\
\hline
\end{tabular}

O cádmio pode causar muitos efeitos indesejados tanto nos seres humanos como em plantas e animais em geral. Estudos mostram que, depois de absorvido, ele se distribui pelo organismo, sendo encontrado nas células sanguíneas, ligado à proteína do soro plasmático e albuminas, além de outras glicoproteínas. Pode acumular em plantas e animais, atingindo o homem por meio da cadeia alimentar acumulando-se nos rins e nos fígados (FERNANDES et al., 2014).

O chumbo $(\mathrm{Pb})$ é um dos contaminantes ambientais mais comuns, tóxico para seres humanos e animais, sem função fisiológica identificada no organismo, entra no corpo principalmente por meio de inalação ou ingestão. Seus efeitos noviços podem afetar praticamente todos os órgãos e sistemas do organismo humano (MOREIRA et al., 2004).

As principais ações tóxicas do $\mathrm{Pb}$ no organismo humano compreendem: biossíntese do grupo heme, sistema nervoso, sistema renal, trato gastrointestinal e fígado. Nas crianças, o efeito atinge o sistema nervoso e nos adultos a exposição ocupacional excessiva os cuidados são com a neuropatia periférica e nefropatia crônica (MOREIRA et al., 2013). Este metal se acumula no organismo formando ligações covalentes (complexos), principalmente com grupos sulfídricos (-SH) de moléculas biológicas, e também com grupos amino e carboxílicos (MACHADO, 2008). A toxidade do alumínio é uma das limitações de plantas em áreas cultiváveis para as diversas espécies de importância agronômica. Das espécies de alumínio, a forma $\mathrm{Al}^{3+}$ é comprovadamente tóxica e o sintoma inicial, e mais nocivo de sua toxidade, é a inibição do crescimento da raiz das plantas (ECHART, 2001).

O Mercúrio encontra-se em sua principal forma catiônica $\left(\mathrm{Hg}^{2+}\right)$, e pode associar-se a partículas em suspensão, que se depositarão em sedimentos nos corpos d'águas, onde os microrganismos convertem esse cátion em dimetilmercúrio $\mathrm{Hg}\left(\mathrm{CH}_{3}\right)_{2}$ uma substância neurotóxica, e esta substância ainda é convertida em metilmercúrio, $\mathrm{HgCH}_{3}$, em função do $\mathrm{pH}$ do meio. O metilmercúrio se difunde e se acumula no tecido adiposo, em um fenômeno conhecido por bioconcentração. No interior do organismo, o metilmercúrio exercerá sua ação tóxica, interagindo com os grupos sulfidrila das enzimas (LIMA et al., 2011).

O ferro é um micronutriente essencial para o crescimento e desenvolvimento das plantas. Quando em excesso, porém, pode induzir a produção e acúmulo de espécies ativas de oxigênio, causando estresse oxidativo, levando a uma redução do crescimento e, portanto, diminuição na produtividade das plantas. A 
toxicidade do ferro não é problema na maioria dos solos, exceto em lugares alagados e onde o minério de ferro está sendo extraído ou beneficiado (JUCOSKI et al., 2016).

A Política Nacional de Resíduos Sólidos, através da Lei oo 12.305 de 02 de agosto de 2010 (BRASIL, 2010), estabeleceu como diretrizes, o incentivo para não geração, redução, reutilização e ao tratamento de resíduos sólidos, bem como a destinação adequada dos rejeitos. Em termos legais, rejeitos: resíduos sólidos que, depois de esgotadas todas as possibilidades de tratamento e recuperação por processos tecnológicos disponíveis e economicamente viáveis, não apresentem outra possibilidade que não a disposição final ambientalmente adequada.

Esta legislação sugere reaproveitamento dos resíduos a fim de minimizar os impactos ambientais, fornecendo matéria prima em longo prazo e baixo custo. Atualmente, o lodo de Estação de Tratamento de Água é tido como um rejeito e na maioria das ETAs e destinado no próprio rio onde ocorre a coleta da água bruta para o processo de tratamento. A Lei 12.305/2010 em seu Art. 3ำ, define a concepção de destinação final ambientalmente como

VII: destinação de resíduos que inclui a reutilização, a reciclagem, a compostagem, a recuperação e o aproveitamento energético ou outras destinações admitidas pelos órgãos competentes do Sisnama, do SNVS e do Suasa, entre elas a disposição final, observando normas operacionais específicas de modo a evitar danos ou riscos à saúde pública e à segurança e a minimizar os impactos ambientais adversos;

VIII: disposição final ambientalmente adequada: distribuição ordenada de rejeitos em aterros, observando normas operacionais específicas de modo a evitar danos ou riscos à saúde pública e à segurança e a minimizar os impactos ambientais adversos.

Este último parágrafo pode ser empregado quando cessado todos as opções sugeridas no parágrafo VII, visto que a opção aterro sanitário não pode ser aplicado para todos os estados, ou municípios. O lançamento do lodo em cursos d'água no próprio rio onde ocorre a captação d'água é o método mais utilizado, porem pode gerar muitos problemas ambientais, e contrapor o artigo 54 da Lei 9.605/98 que estabelece que o lançamento de resíduos gerados em ETAs em corpos d'água sem aprovação de órgãos ambientais, é considerado crime ambiental em virtude da poluição e consequente danos à fauna aquática (ACHON et al., 2013).

\section{Panorama global de utilização do lodo de ETA}

Na Holanda, desde 1989, apenas $2 \%$ do lodo gerado pelas estações de tratamento era lançada nos cursos d'água, enquanto $12 \%$ eram utilizados na agricultura e $7 \%$ utilizado no controle de gás sulfídrico (PEREIRA, 2011). Os EUA apresentam uma proporção maior na utilização do lodo de ETA na agricultura, sendo $25 \%$ da geração, e $11 \%$ são tidos como destino os corpos hídricos, $24 \%$ descarga no sistema público de esgoto, $20 \%$ em aterros sanitários e $20 \%$ em outros tipos de destinação (AWWA, 2012).

Na França, $6 \%$ tem como destino a aplicação no solo, 53\% é utilizado na construção civil, $29 \%$ vão para o sistema público de esgoto, $13 \%$ aterro sanitário (ADLER, 2002). No Brasil o aproveitamento do lodo ainda não se tornou uma prática entre os responsáveis pela geração desse resíduo, e seu aproveitamento possui índices insignificantes (ROCHA, 2016). Segundo dados do IBGE (2010), cerca de 62\% do lodo geração 
pelas estações de tratamento são dispostos em curso d'água, e apenas 5,9\% possui uma destinação adequada, tais como aterro sanitário, incineração ou reaproveitamento. Por meio da figura 1, pode-se notar com maior profundidade os principais tipos de destinação

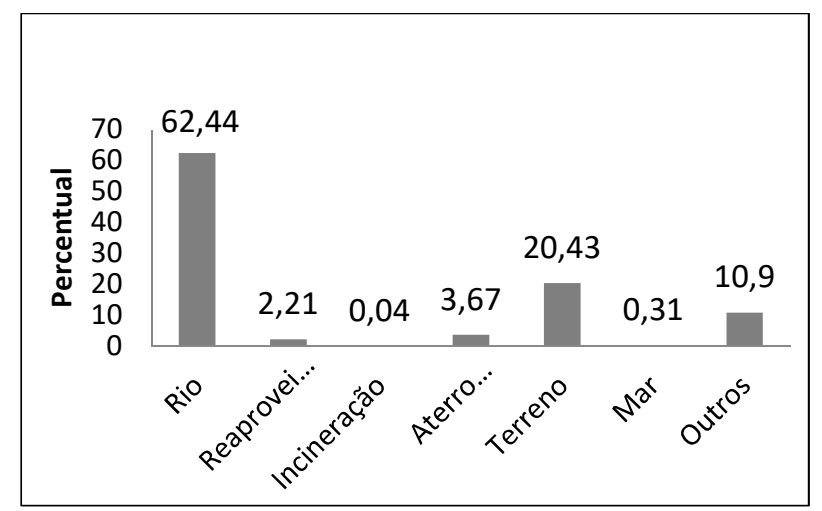

Figura 2: Destino final do lodo de ETA nos municípios brasileiros em percentual.

Achon et al. (2013) realizou um trabalho em cinco ETAs localizadas em São Paulo, e concluiu que todas elas refletem um quadro comum no Brasil, não dimensionam a quantidade de resíduos gerados, poucas avaliam as características do lodo produzido e destinam corretamente esses resíduos o que dificulta e em, muitos casos podem impossibilitar o uso de indicadores como ferramentas de gestão. De acordo com o trabalho de Souza et al. (2017), o lodo não pode ter como destino diretamente nos corpos receptores, pois o nível de sólidos sedimentáveis é superior ao permitido pela Resolução no 430/2011, em todas as etapas, em duas ETAs analisadas.

Esta resolução dispõe sobre condições, parâmetros, padrões e diretrizes para gestão do lançamento de efluentes em corpos de água receptores, alterando parcialmente e complementando a Resolução $\mathrm{n}^{\circ}$. 357, de 17 de março de 2005 (CONAMA, 2005). A destinação inadequada de lodo no corpo hídrico aumenta a quantidade de sólidos nos corpos d'água, altera o pH (geralmente diminui), aumenta a cor da água além da turbidez, causa também a liberação de odores, contribui para o aumento da concentração de alumínio e ferro (TALLINI JUNIOR, 2009).

\section{Tipos de destinação ambientalmente correta}

A destinação do lodo de uma estação de tratamento de água é uma das atribuições mais difíceis para o administrador do serviço de água, pois envolve custos elevadíssimos e restrições ao meio ambiente (RICHTER, 2001). Dentre as alternativas, podem-se destacar a produção de cerâmica vermelha, aterros sanitários e construção civil e utilização na agricultura e produção de mudas.

\section{Utilização do lodo de Estação de Tratamento de Água na produção de cerâmicas vermelha}

Conforme descreve Tallini Junior (2009), no segmento da construção civil, o lodo pode ser utilizado na fabricação de cimento e concreto, e pode ser aplicado na confecção de peças cerâmicas, tais como tijolos, telhas e outros blocos. Algumas destas ideias surgiram em países da Europa, Japão e Austrália, e com algumas 
ressalvas, quase todas mostram-se viáveis, e eficientes, muitas das vezes, trazendo economia significativa, quando usadas para substituir a disposição em aterros sanitários (KATAYAMA, 2012).

Deve-se ressaltar que alguns trabalhos demonstraram pontos negativos na utilização para produção de cerâmicas. Tartari et al. (2011) sugeriu que o lodo gerado na ETA da unidade Tamanduá de Foz do Iguaçu, Paraná, não pode ser utilizado como componente majoritário em massas cerâmicas, em virtude de suas características desplastificantes, grande porcentagem de grãos de tamanho grosseiro e elevada perda ao fogo.

Seguindo esta mesma linha de raciocínio, Vieira et al. (2008) sugeriu que a incorporação de lodo de ETA aumenta os defeitos microestruturais da cerâmica argilosa. Isto ocorre, sobretudo, devido à eliminação de matéria orgânica durante a etapa de queima. Porém, seus resultados obtidos comprovaram que a reciclagem de lodo de ETA em cerâmica argilosa deve ser realizada em pequenos percentuais para minimizar seu efeito deletério na qualidade da cerâmica. Já os resultados de Ferrari (2007) indicam que a concentração de $30 \%$ de lodo na produção de cerâmica é inviável, porém a concentração de 5\% é indicada, pois apresenta resultados próximos aos obtidos sem a adição de lodo.

Os trabalhos de Rodrigues et al. (2011) indicam que, apesar do lodo da ETA apresentar uma constituição mineralógica semelhantes às argilas empregadas em cerâmica vermelha, sua incorporação em mistura com argila não resulta em incremento das propriedades físicas e mecânicas como o esperado. A incorporação não deve ultrapassar a 10\% de lodo para não afetar a qualidade do produto final. Deste modo, o lodo por si só não pode ser usado como componente majoritário em massas cerâmicas, porém pode ser incorporado como aditivo em massas argilosas (KATAYAMA, 2012).

\section{Aterro e construção civil}

O lodo pode ser utilizado na construção civil, em contrapisos, blocos de placas de vedação, como decoração de estai para rede de distribuição de energia elétrica, tampas de concreto para cobertura de fossas, calçadas e pavimentos residenciais, porem sua incorporação dentro do limite de 4 a $8 \%$ não reduz matéria prima, como areia, cimento e brita (HOPPEN et al., 2006). O aterro sanitário é considerado, por muitos, como o melhor meio de disposição final do lodo, no sentido de conter a contaminação ao ambiente. Porém, deve-se considerar que, no Brasil, a maioria dos aterros, já não é capaz de receber os resíduos sólidos. Além das altas taxas cobradas pelos aterros para receber o lodo, torna recomendável o estudo de alternativas de destinação do lodo de ETAs (TALLINI JUNIOR, 2009).

\section{Utilização do lodo de Estação de Tratamento de Água na agricultura}

O lodo pode ser usado na recuperação do solo, a fim de reabilitá-lo para o crescimento de plantas, ao contrário do uso na agricultura, onde ele funciona como um condicionador (TALLINI JUNIOR, 2009). De acordo com Richter (2001), a técnica de esparramar o lodo no solo natural ou na agricultura, é considerada uma alternativa de disposição viável, principalmente quando o lodo aplicado é de sulfato de alumínio ou de 
cal, atua-se como condicionador do solo, tornando-se o solo mais poroso, permitindo mais umidade e coesividade.

Portanto, a SANEPAR, afirma que o método de destinar o lodo no solo pode ajudar a recuperar áreas degradadas, pois o mesmo é composto por elementos do solo e possui nutrientes para o desenvolvimento das plantas (TARTARI et al. 2011), de acordo com os estudos de Machado et al. (2004), em que foi constatado a presença de matéria orgânica, macronutrientes (nitrogênio, potássio, fósforo, cálcio, magnésio e enxofre) e micronutrientes (boro, cobre, ferro, manganês, zinco) nesse resíduo.

E quando comparado com os valores no lodo em relação aos compostos constituintes dos resíduos orgânicos de lixo urbano e de esterco bovino, normalmente utilizado como insumos agrícolas, o lodo apresenta valores inferiores. Porém, quando comparado à composição do solo da região em estudo os valores de nitrogênio, fósforo, potássio e matéria orgânica encontrada no lodo foram superiores. Assim, Machado et al. (2004) sugere a utilização do lodo para fins agrícolas, pois a composição deste resíduo apresenta elementos essenciais ao desenvolvimento dos vegetais.

Alguns benefícios associados a aplicação dos lodos de ETAs em solos agrícolas são: melhoria estrutural do solo; ajuste de $\mathrm{pH}$; adição de traços de minerais; aumento da capacidade de retenção de água e melhoria das condições de aeração do solo. Porém, estudos têm demonstrado que o lodo de ETAs, quando aplicado ao solo agrícola, apresenta tendência de reagir e indisponibilizar à planta, o fósforo presente no solo (TSUTYA, 2001).

Deve-se ressaltar que a utilização do lodo para produção de alimentos exige avaliação físico-química e identificação da composição deste resíduo, pois alguns metais pesados podem se acumular nas partes comestíveis das plantas que são consumidas pelos homens e animais. A absorção dos metais pesados pelas plantas varia conforme a espécie, abrindo a possibilidade de adaptar os cultivos conforme o nível e o tipo de contaminação do solo (MACHADO, 2008).

\section{Mudas em viveiros}

Pode ser aproveitado para produção de mudas em concentrações de até $50 \%$. Esta alternativa pode se mostrar viável, gerando rendas para os viveiros e incentivo à produção de mudas de arvore, embora o maior interesse seja ambiental e ecológico, visto que toneladas deste lodo são descartadas inadequadamente, gerando vários danos ao meio ambiente (FIGUEIREDO NETO, 2011). Padilha et al. (2017) avaliou a aplicação do lodo para o cultivo de mudas mostra-se relevante, principalmente do ponto de vista da recuperação de nutrientes presentes no lodo, podendo, contudo, se tornar uma alternativa de valorização deste tipo de resíduo. Porém, deve-se destacar que as mudas utilizadas não podem ter relação com a cadeia alimentar, devido à capacidade das plantas em absorver metais tóxicos. Sendo assim, a utilização de espécies madeireira como eucalipto e espécies ornamentais como ipê pode ser uma excelente alternativa.

Mudas para fins de arborização ou produção comercial, evitam que o ser humano possa ingerir, de alguma forma, os metais pesados presentes no lodo de ETA. O arsênio, por exemplo, é um metaloide amplamente distribuído na crosta terrestre, e é encontrado em forma de sulfeto em grandes variedades de 
minerais, é utilizado como raticida, e em alguns casos, como medicação homeopática ou alopática. As fontes de contaminação abrangem minerais, rochas, solos, água e alimentos (ANDRADE et al., 2015). Seu alto nível de toxicidade é bem conhecido, pois compostos de arsênio são facilmente absorvidos, tanto oralmente quanto por meio de inalação, sendo a extensão da absorção dependente da solubilidade do composto (BARRA et al., 1999).

O problema de saúde provocado pelo referido metal depende da quantidade ingerida, dose, frequência e tempo de absorção, já que é excretado, principalmente, pelo fígado e rins, atua no organismo como inibidor da respiração celular, pois pode há um grande acumulo nas mitocôndrias das células e pode comprometer funções da síntese proteica (ANDRADE et al., 2015).

\section{CONCLUSÕES}

O lodo de ETA é um resíduo de características tóxicas. Portanto, sua destinação deve atender as diretrizes da PNRS - Lei 12.305/2010, priorizando a possibilidade de redução, reuso e reciclagem. Tendo em vista as restrições da legislação para lançamento dos resíduos de ETAs em corpos d'água, o volume de água perdido e os impactos ambientais associados a essa prática, há uma crescente necessidade de proporcionar uma destinação adequada ou um uso produtivo a esses resíduos, minimizando também a quantidade de subproduto gerado.

Assim, a utilização para produção de mudas pode inferir significativamente na disposição final deste resíduo, uma vez que várias espécies principalmente de ornamentação e produção de matéria-prima podem suportar as concentrações de metais tóxicos presentes no lodo. Porém, diante da complexidade do assunto, não há como estabelecer uma solução única para o tratamento e disposição final do lodo das ETAs, pois alguns fatores devem ser observados, desde análises laboratoriais até a logística para destinação.

\section{REFERÊNCIAS}

ABNT. Associação Brasileira de Normas Técnicas. NBR 10004: Resíduos Sólidos: Classificação. Rio de Janeiro: ABNT, 2004.

ACHON, C. L.; BARROSO, M. M.; CORDEIRO, J. S.. Leito de drenagem: sistema natural para redução de volume de lodo de estação de tratamento de água. Engenharia Sanitária e Ambiental, Rio de Janeiro, v.13, n.1, 2008.

ACHON, C. L.; BARROSO, M. M; CORDEIRO, J. S.; Resíduos de estações de tratamento de água e a ISO 24512: desafio do saneamento brasileiro. Engenharia Sanitária e Ambiental, v.18 n.2, p.115-122, 2013.

ADLER, C.. Centrality dependence of high Thadronsuppression in Au+ Aucollisionsatsqrt (sNN)=130 GeV. ArXiv, v.1, 2002.

ANDRADE, C. F.; SILVA, C. M.; OLIVEIRA, F. C.. Gestão ambiental em saneamento: uma revisão das alternativas para tratamento e disposição do lodo de ETA e seus impactos na qualidade das águas. In: CONGRESSO BRASILEIRO DE GESTÃO AMBIENTAL, 5. Anais. Belo Horizonte: 2014.
ANDRADE, D. F.; ROCHA, M. S.. A toxicidade do Arsênio e Sal Natureza. Osvaldo Cruz, v.10, 2015.

ASSIS, R. A.. Aperfeiçoamento e aplicações de uma metodologia para análise de especiação de arsênio por eletroforese capilar com detector de ICPMS. Rio de Janeiro: 2006.

AWWA. American Water Works Association. For the Examination of Water and Wastewter. Denver: AWWA, 2012.

BARRA, C. M.; SANTELLI, R. E.; ABRÃO, J. J.; GUARDIA, M.. Especiação de Arsênio: uma revisão. Química Nova, v.23, n.1, 2000.

BERNARDO, L.; BERNARDO, A.. Métodos e técnicas de tratamento de água. 2 ed. São Carlos: Rima, 2005.

BITTENCOURT, S.; SERRAT, B. M.; AISSE, M. M; MARIN, L. M. K. S.; SIMÃO, C. C.. Aplicação de lodos de estações de tratamento de água e de tratamento de esgoto em solo 
degradado. Artigo técnico. Engenharia Sanitária e Ambiental, v.17, n.3, 2012.

BRASIL. Lei n.12305 de 02 de agosto de 2010. Política Nacional de Resíduos Sólidos. Brasília: DOU, 2010.

CARLOS, E.; GALVÃO, A.. Saneamento Básico em Rondônia: Deficiências no acesso à água tratada e esgotos nas maiores cidades são críticos para a saúde das pessoas. São Paulo: Instituto Trata Brasil, 2015.

CONAMA. Conselho Nacional do Meio Ambiente. Resolução n.357 de 17 de março de 2005. Dispõe sobre a classificação dos corpos de água e diretrizes ambientais para o seu enquadramento, bem como estabelece as condições e padrões de lançamento de efluentes, e dá outras providências. Brasília: CONAMA, 2005.

CONCEIÇÃO, L. D. C. S.; SERENO, M. J. C. M.; NETO, J. F. B.. Tolerância ao alumínio em plantas: toxicidade, mecanismos e genes em espécies cultivadas. Agrociência, Pelotas, v.14, p.1-10, 2008.

ECHART, C. L.; CAVALLI-MOLINA, S.. Fitotoxicidade do alumínio: efeitos, mecanismo de tolerância e seu controle genético. Ciência Rural, v.31, n.3, p.531-541, 2001.

FERNANDES, L.; MAINIER, F.. Os riscos da exposição ocupacional ao Cádmio. Sistemas \& Gestão, v.9, n.2, p.194199, 2014.

FERRARI, N. T.. Incorporação do Lodo da Estação de Tratamento de Água (ETA II) do Município de Rio Claro-SP, na Argila para produção de Cerâmicas Vermelha. Monografia (Graduação) - Universidade Estadual Paulista 'Júlio de Mesquita Filho', Rio Claro, 2009.

FRANCO, E. S.. Avaliação da influência dos coagulantes sulfato de alumínio e cloreto férrico na remoção de turbidez e cor da água bruta e sua relação com sólidos na geração de lodo em estações de tratamento de água. Dissertação (Mestrado em Engenharia Ambiental) Universidade Federal de Ouro Preto, Ouro Preto, 2009.

HOPPEN, C.; PORTELLA, K. F.; JOUKOSKI, A.; TRINDADE, E. M.; ANDREÓLI, C. V.. Uso de lodo de estação de tratamento de água centrifugado em matriz de concreto de cimento portland para reduzir o impacto ambiental. Química Nova, v.29, n.1, p.79, 2006.

IBGE. Instituto Brasileiro de Geografia e Estatística. Pesquisa Nacional de Saneamento Básico. Rio de Janeiro: IBGE, 2010.

JANUARIO, F. G.; FILHO, S. S.. Planejamento e aspectos ambientais envolvidos na disposição final de lodos das estações de tratamento de água da Região Metropolitana de São Paulo. Engenharia Sanitária e

Ambiental, v.12, n.2, 2007.

JUCOSKI, G. O.; CAMBRAIA, J.; RIBEIRO, C.; OLIVEIRA, J. A.. Excesso de ferro sobre o crescimento e a composição mineral em Eugenia uniflora L. Ciência Agronômica, v.47, n.4, p.720-728, 2016.

KATAYAMA, V. T.. Quantificação da Produção de Lodo de Estações de Tratamento de Água de Ciclo Completo: uma análise crítica. Dissertação (Mestrado) - Universidade de São Paulo, São Paulo, 2012.

KLOC, A. P.; LAIRD, Y. V.. Avaliação do impacto de lodo de estação de tratamento de água (ETA) na qualidade das águas do arroio pilão de pedra. Monografia (Graduação em Engenharia Química) - Universidade Tecnológica Federal do Paraná, Ponta Grossa, 2017.

LIMA, V. F.; MERÇON, F.. Metais Pesados no Ensino de Química. Química Nova na Escola, v.33, n.4, 2011.

LOPES, J. C.; SERRA, J. C. V.. Adensamento mecânico e desidratação do lodo da ETA-6 por filtro prensa. Engenharia Ambiental: Pesquisa e Tecnologia, v.13, n.1, 2016.

MACHADO, L.; PEREIRA, J. A. R.; PONTE, M. X.; LOPES, L. D. N. A.. Avaliação do aproveitamento agrícola do lodo produzido na ETA Bolonha-RMB. In: CONGRESSO BRASILEIRO DE CIÊNCIA E TECNOLOGIA EM RESÍDUOS E DESENVOLVIMENTO SUSTENTÁVEL. Anais. São Paulo: FAPESP, 2004.

MACHADO, S. S.; BUENO, P. R. M.; OLIVEIRA, M. B.; MOURA, C. J.; MOURA, C. J.. Concentração de chumbo em alface cultivada com diferentes adubos orgânicos. Revista Brasileira de Produtos Agroindustriais, v.10, n.1, p.63-70, 2008.

MOREIRA, F. R.; MOREIRA, J. C.. A cinética do chumbo no organismo humano e sua importância para a saúde. Ciência \& Saúde Coletiva, v.9, n.1, p.167-181, 2004.

MOREIRA, F. R.; MOREIRA, J. C.. Os efeitos do chumbo sobre o Organismo humano e seu significado para a saúde. Environmental pollution, v.181, n.2, p.226-232, 2013.

OLIVEIRA, I. Y. Q.; RONDON, O.. Diagnóstico da gestão de lodo de estação de tratamento de água em Mato Grosso do Sul. Interações, Campo Grande, v.17, n.4, p.687-698, 2016.

PADILHA, F. T.; MODOLO, R. C. E.. Utilização de lodo de estação de tratamento de água como substrato para produção de mudas. In: FÓRUM INTERNACIONAL DE RESÍDUOS SÓLIDOS. Anais. São Paulo: FAPESP, 2017.

PAVANELLI, G.. Eficiência de diferentes tipos de coagulantes na coagulação, floculação e sedimentação de água com cor ou turbidez elevada. Tese (Doutorado) - Universidade de São Paulo, São Paulo, 2001.

PEREIRA, S. L. M.. Características físicas, químicas e microbiológicas do lodo das lagoas da ETA Gramame. Dissertação (Mestrado) - Universidade Federal da Paraíba, João Pessoa, 2011.

PORTELLA, K. F.; ANDREOLI, C. V.; HOPPEN, C.; SALES, A.; BARON, O.. Caraterização físico-química do lodo centrifugado da estação de tratamento de água Passaúna Curitiba-PR. In: CONGRESSO BRASILEIRO DE ENGENHARIA SANITÁRIA AMBIENTAL, 22. Anais. Joinville: 2003.

RICHTER, C. A.. Água: métodos e tecnologia de tratamento. São Paulo: Edgard Blücher, 2009. 


\section{RICHTER, C. A.. Tratamento de Lodo de Estação de}

Tratamento de Água. São Paulo: Editora Edgard Blücher, 2001.

ROCHA, M. A. F.. Uso do tratamento de resíduo da estação de tratamento de água de Ji-Paraná/RO como material cimentício. Dissertação (Mestrado em Engenharia Civil) Universidade Federal do Amazonas, Manaus, 2016.

RODRIGUES, R. A.; MARTINS, B. E. D. B. S.; COUTO, V. M. N. P.; CAMPOS, J. C.; ALMEIDA, V. C.. Avaliação do reaproveitamento do lodo de estação de tratamento de água na indústria de cerâmica vermelha. In: CONGRESSO BRASILEIRO DE CERÂMICA, 55. Anais. Porto de Galinhas: 2011.

SCALIZE, P. S.; FIGUEIREDO NETO, A.; RIOS, F. P.; ALBUQUERQUE, A. J. C.. Estudo da influência da temperatura da água bruta na eficiência do coagulante químico. Sodebras, v.7, n.80, 2012.

SILVA, G. A.; SANTOS, M. J.; CARNIELLO, M. F.; SILVA, J. L.. Caracterização do Sistema de Abastecimento de Água de Porto Velho/RO. In: ENCONTRO LATINO-AMERICANO DE INICIAÇÃO CIENTIFICA, X ENCONTRO LATINO AMERICANO DE PÓS GRADUAÇÃO E IV ENCONTRO LATINO AMERICANO DE INICIAÇÃO CIENTIFICA JUNIOR, 14. Anais. João Pessoa: UFPB, 2010.

SUGUINO, E.; FREITAS, A. P.; VASQUES, H.. Potencial de Uso do Lodo de Estações de Tratamento de Água e Esgoto. Pesquisa e Tecnologia. Apta Regional, São Paulo, 2013.
TALLINI JUNIOR, W. M.. Desenvolvimento de novos materiais cerâmicos a partir do lodo de estações de tratamento de água, microesfera de vidro de jateamento, sais de neutralização de ácidos de baterias e areia de fundição. Dissertação (Mestrado em Engenharia e Ciência dos Materiais) - Universidade Federal do Paraná, Curitiba, 2009.

TARTARI, R.; DIAZ-MORA, N.; MÓDENES, A. N.; PIANARO, S. A.. Lodo gerado na estação de tratamento de água Tamanduá, Foz do Iguaçu, PR, como aditivo em argilas para cerâmica vermelha: Parte II: incorporação do lodo em mistura de argilas para produção de cerâmica vermelha. Cerâmica, v.57, n.344, p.387-394, 2011.

TSUTUYA, M. T.; HIRATA, A. Y.. Aproveitamento e disposição final de lodos de estação de tratamento de água do Estado de São Paulo. In: CONGRESSO BRASILEIRO DE ENGENHARIA SANITÁRIA E AMBIENTAL, 21. Anais. João Pessoa: ABES, 2001.

VAZ, L. G. L.; KLEN, M. R. F.; VEIT, M. T.; SILVA, E. A.; BARBIERO, T. A.; BERGAMASCO, R.. Avaliação da eficiência de diferentes agentes coagulantes na remoção de cor e turbidez em efluente de galvanoplastia. Eclética Química, São Paulo, v.35, n.4, 2010.

VIEIRA, C. M. F.; MARGEM, J. I.; MONTEIRO, S. N.. Alterações microestruturais de cerâmica argilosa incorporada com lodo de ETA. Matéria, v.13, n.2, p.275-281, 2008.

A CBPC - Companhia Brasileira de Produção Científica (CNPJ: 11.221.422/0001-03) detém os direitos materiais desta publicação. Os direitos referem-se à publicação do trabalho em qualquer parte do mundo, incluindo os direitos às renovações, expansões e disseminações da contribuição, bem como outros direitos subsidiários. Todos os trabalhos publicados eletronicamente poderão posteriormente ser publicados em coletâneas impressas sob coordenação da Sustenere Publishing, da Companhia Brasileira de Produção Científica e seus parceiros autorizados. Os (as) autores (as) preservam os direitos autorais, mas não têm permissão para a publicação da contribuição em outro meio, impresso ou digital, em português ou em tradução. 